\title{
O EXERCÍCIO DA AUTONOMIA: UM CAMINHO PARA A RESISTÊNCIA E CONSTRUÇÃO DE SIGNIFICADOS
}

\author{
THE EXERCISE OF AUTONOMY: \\ A PATH TO RESISTANCE AND THE CONSTRUCTION OF MEANING
}

\begin{abstract}
Sônia Regina Guaraldo
Aluna regular do programa de pós-graduação em nível de doutorado na Unesp de Presidente Prudente, possui mestrado em Educação pela Universidade de São Paulo - USP - na área de didática, Teorias de Ensino e Práticas escolares. Presidente Prudente - SP - Brasil. soniareginaguaraldo@gmail.com
\end{abstract}

\begin{abstract}
Alberto Albuquerque Gomes
Professor do Programa de Pós-graduação em Educação (Mestrado e Doutorado) e do curso de Pedagogia da Faculdade de Ciências e Tecnologia - UNESP. Membro do Conselho Editorial da revista Nuances (Presidente

Prudente). Tem experiência na área de Sociologia da Educação atuando principalmente nos seguintes temas: formação de professores, representações sociais, políticas públicas e pedagogia. Presidente Prudente - SP - Brasil. alberto.gomes@unesp.br
\end{abstract}

Resumo: O presente artigo pretende discutir o exercício da autonomia dos profissionais de educação na construção de significados frente a propostas formuladas em nível macro nas estruturas de governo. Para tanto, à luz dos pressupostos foucaultianos, parte-se da contextualização das questões educacionais no conjunto da sociedade do desempenho, buscando-se compreender as múltiplas interferências da economia neoliberal na educação como também compreender como o sujeito se constitui frente às relações de poder, no sentido de "conduzir ações de outrem". Tais pressupostos, são ampliados por Basil Bernstein, buscandose compreender como mecanismos de poder e controle interferem nas relações entre os sujeitos de um mesmo ou de diferentes níveis hierárquicos, gerando a partir de vozes específicas a reprodução/produção de determinadas mensagens. Conclui-se que o exercício da autonomia e uso consciente da razão são possíveis a partir de um posicionamento racional, teórico e ético frente às grandes problemáticas atuais.

Palavras-chave: Autonomia. Poder. Controle. Política de Formação.

Abstract: the present article aims to discuss the exercise of autonomy among education professionals in the construction of meaning vis-à-vis proposals that are formulated at a macro level inside governmental structures. To that end, in light of Foucaultian assumptions, I begin with the contextualization of educational issues in our society of performance as whole, seeking to understand the multiple interferences of neoliberal economics in education, as well as to understand how the subject is constituted in the face of power relations as they pertain to of "conducting the actions of others". Such assumptions are amplified by Basil Bernstein, who seeks to understand how power and control mechanisms interfere in the relationship among subjects within the same or different hierarchical levels, generating \the reproduction/production of certain messages from specific voices. Finally, it may be concluded that the exercise of autonomy and the conscious use of reason are possible when embedded in a rational, theoretical and ethical stance regarding major current issues.

Keywords: Autonomy. Power. Control. Teacher training policy.

\section{Para citar - ABNT NBR 6023:2018}

GUARALDO, Sônia Regina; GOMES, Alberto Albuquerque. O exercício da autonomia: um caminho para a resistência e construção de significados. Cadernos de Pós-graduação, São Paulo, v. 19, n. 1, p. 32-44, jan./jun. 2020. Disponível em: https://doi.org/10.5585/cpg.v19n1.11403. 


\section{Introdução}

O interesse da discussão da autonomia dos sistemas municipais de educação a partir dos pressupostos focaultianos centra-se em compreender as possibilidades e os limites de seu exercício frente aos desafios em oferecer formação continuada a professores alfabetizadores e à implementação das políticas de formação concebidas em nível macro. O tema é foco central da pesquisa de doutorado1 que tem como principais referências o Modelo de Reprodução e Transformação Cultural e o Modelo do Discurso Pedagógico, desenvolvido por Basil Bernstein e a abordagem do ciclo de políticas, proposta por Stephen Ball. Os autores, que discutem como os discursos pedagógicos se estruturam, sofrem grande influência da teoria de Foucault, principalmente no que se refere ao discurso como ferramenta de disputa de poder no campo da educação.

Conforme o pensamento de Ball e Bernstein, entendemos a importância da compreensão das formas de regulação da sociedade como um todo e não apenas dos eventos circunscritos ao contexto educacional para a interpretação das múltiplas influências que as políticas relacionadas à educação sofrem, especialmente em sua fase de formulação. Para nos apoiar nessa discussão, recorreremos ao conceito de governamentalidade formulado por Foucault, que se torna essencial para a compreensão das múltiplas dimensões e estratégias de interferência tanto nas macropolíticas como nas micropolíticas, uma vez que agem sobre a população, estão presentes nas relações entre indivíduos, gerando uma ação do indivíduo em relação a si mesmo. Para Foucault a palavra governamentalidade significa

\footnotetext{
I - o conjunto constituído pelas instituições, procedimentos, análises e reflexões, cálculos e táticas que permitem exercer essa forma bastante específica e complexa de poder, que tem por alvo principal a população, por forma principal de saber a economia política e por instrumentos técnicos essenciais os dispositivos de segurança. II - a tendência que em todo o Ocidente conduziu incessantemente, durante muito tempo, à preeminência desse tipo de poder, que se pode chamar de governo, sobre todos os outros: soberania, disciplina, etc. - e levou ao desenvolvimento de uma série de aparelhos específicos de governo e de um conjunto de saberes. [...]. (FOUCAULT, 1979, p. 291-292).
}

Pode-se compreender como os valores da sociedade do desempenho, alicerçadas na lógica da economia neoliberal, sobretudo a americana, governa a forma de viver das pessoas em todos os níveis, exercendo grande influência na configuração das políticas públicas, como é o caso da educação. Foucault promove uma análise genealógica sobre as diferentes formas históricas e complementares de condução da população. Para ele importa pensar o Estado a partir da noção de governo das coisas e das pessoas. "[...] por governo, compreendo o conjunto das instituições e práticas por meio das quais se guiam os homens desde a administração até a educação". Trata-se, 
portanto, de "um conjunto de procedimentos, técnicas e métodos que garantem a condução dos homens" (FOUCAULT, 1976).

Ora, para os neoliberais, a análise econômica deve consistir, não no estado desses mecanismos, mas no estudo da natureza e das consequências do que chamam de opções substituíveis, isto é, o estudo e a análise da maneira como são alocados recursos raros para fins que são concorrentes, isto é, para fins que são alternativos, que não podem se superpor uns aos outros". (FOUCAULT, 1988 p. 306)

Compreender o neoliberalismo significa mais do que compreender o conceito sobre como a economia se organiza. Mais que isso, significa compreendê-lo como uma maneira de ser e estar no mundo. Ainda que, como aponta Foucault, o neoliberalismo não seja exatamente sucedâneo ao liberalismo sob o ponto de vista de substituição de uma forma, mas um "recobrimento parcial e em vários âmbitos conservativos de uma forma pela outra" (VEIGA-NETO, 2011 p. 38), a diferença básica entre eles reside no fato de que no liberalismo seu princípio de inteligibilidade centra-se no exercício da economia num ambiente o mais livre possível e, no neoliberalismo, o princípio da inteligibilidade é representado pela competição, num entendimento de que os processos econômicos não são mais espontâneos, naturais e precisam ser incentivamos e, porque não dizer, ensinados.

A organização da sociedade a partir do tom que é dado pelo pensamento neoliberal sinaliza para outra lógica de funcionamento dos processos de organização dos tempos relacionados ao trabalho e ao descanso. Na modernidade líquida caracterizada por essa lógica de sociedade ditada pela economia, as formas de organização dos tempos de trabalho se alteram, tornando-se nãolineares e imprevisíveis e os modelos que estruturavam a "fábrica" com seus processos de produção localizados em tempos e espaços definidos dão lugar à lógica da empresa.

O deslocamento da ênfase em uma instituição de (re)produção de mercadoria - a fábrica
- para uma instituição de inovação - a empresa - de um trabalho centrado no uso do
corpo para um trabalho que privilegia o uso do cérebro, sinalizaria a passagem do
capitalismo industrial, também chamado de capitalismo fordista para o capitalismo
cognitivo (CORSANI, 2003). No capitalismo industrial, a inovação era exceção. Seu
funcionamento baseava-se na reprodução de mercadorias padronizadas. No capitalismo
cognitivo, a invenção torna-se um processo continuado, a exceção torna-se regra. O
acontecimento, antes neutralizado, domina e organiza o capitalismo cognitivo. (VEIGA-
NETO, 2011, p. 43)

Essa nova maneira de compreender o ser e estar no mundo impulsiona uma profunda modificação nos valores que orientam comportamentos, determinando expectativas de vida, de família, de relacionamento. Marcado por processos de presentificação e satisfação imediata, o prazer aspirado pela maioria encontra-se na competição, no vencer sempre, na superação constante do outro e de si mesmo. Para esse indivíduo da sociedade performática, nenhuma meta vencida 
será o bastante e a competitividade marcará o principal valor verificado nessa sociedade do desempenho.

Como consequência dessa nova forma de enxergar a economia baseada na competição, têm-se um novo modelo de sociedade; a ênfase que no liberalismo centrava-se nos produtos, agora recai sobre os consumidores. Desse modo, consumir não significa mais comprar e consumir. Como o ato do consumo vem carregado de valores, comprar e consumir significa pertencer a um novo mundo. Conforme analisa Bauman (2008, apud VEIGA-NETO, 2011 p. 39) “[...] para uma sociedade que proclama que a satisfação do consumidor é seu único motivo e seu maior propósito, um consumidor satisfeito não é motivo, nem propósito, mas uma ameaça mais apavorante”.

\section{Neoliberalismo e o modo de organizar o pensamento educacional}

Considerando as formas ditadas por essa nova maneira de estar no mundo, de se relacionar, de trabalhar influencia diretamente a escola, muda-se substancialmente a forma como se concebe conhecimento e sua aquisição pelos alunos. Na sociedade do desempenho, a escola não detém mais o privilégio na produção das subjetividades, uma vez que crianças e jovens se veem expostos a novos comportamentos, cujos valores são por vezes, conflitantes com os apresentados pelas escolas. A própria escola, ao centrar sua didática na pedagogia dos projetos, guiada pelo pressuposto do atendimento aos interesses dos alunos, estabelece um rompimento com o desenho do modelo disciplinar que caracterizou a educação ao longo da história, onde os desejos estavam sempre adiados para o futuro.

Ocorre que mesmo esse interesse, sempre limitado pelas intervenções da escola e do professor, que limitava a liberdade de escolha a um pacote de opções, liga-se aos valores que fundamentam a economia neoliberal em que as pessoas não são mais caracterizadas como "sujeitos da obediência", mas como sujeitos do desempenho e da produção” (HAN, 2015 p.23). O indivíduo dessa nova sociedade é descrito por Han como o indivíduo da positividade, livre de qualquer instância externa de controle que lhe impõe obrigações; "[...] é senhor e soberano de si mesmo". (HAN, 2015 p. 29).

Ao mesmo tempo, a liberdade oferecida aos sujeitos da sociedade do desempenho é representada por outras formas de coação, exercida pelo próprio indivíduo sob forma de uma eficiente autoexploração, cujas estruturas coercitivas, transformar-se-ão em violência e no que se refere às configurações do trabalho docente, em crescente processo de precarização, marcado pela flexibilização, substituibilidade, desqualificação, marginalização social, esvaziamento político e enfraquecimento associativo e sindical transformando os professores em monitores de projetos, gestores de competências, atendendo a uma demanda de mercado, uma vez que "as empresas de 
ponta e as organizações flexíveis precisam de indivíduos capazes de aprenderem novas capacitações” (SENNETT 2006, p.107 apud VEIGA-NETO, 2011 p. 43 ).

A ideia do "aprender a aprender" relaciona-se diretamente com a ideia do investimento no capital humano e, gerir as técnicas desse investimento, torna-se tarefa da escola. Nesse processo de presentificação, o próprio conhecimento é um elemento com prazo de validade determinado, tornando-se ultrapassado no momento mesmo em que é produzido, um conhecimento utilitário, que será gerado com a finalidade de produzir cidadãos aptos à competição.

O que ocorre é que a precarização do trabalho docente, gerada pelos processos acima citados, tem feito com que a educação oferecida à população, sobretudo às camadas menos favorecidas não se concretize nos termos da qualidade desejada, nem mesmo nos termos impostos pela sociedade do desempenho que requer cidadãos formados para fazer girar a máquina econômica. As desigualdades sociais e as condições de formação inicial e de trabalho dos professores impedem até mesmo que a escola prepare para a competição. Trata-se de uma escola fracassada.

Nesse contexto a formação contínua surge como uma forma de compensar as lacunas deixadas pelo histórico de formação do professor e torna-se central para recuperar minimamente a qualidade educacional oferecida nos moldes ditados pela economia de mercado e em todas as esferas de governo, são comuns as iniciativas que objetivam preencher as lacunas deixadas pela formação inicial. A exemplo disso, podem ser citados os vários movimentos e programas que se efetivaram nas últimas décadas, como a criação da Rede Nacional de Formação Continuada (PNAIC), em 2004, o Proletramento, a Formação no Pacto Nacional pela Alfabetização na Idade Certa, entre outros. Reconhece-se que programas como o PNAIC podem representar para os sistemas municipais de ensino um apoio técnico especializado para a orientação e o acompanhamento dos processos de formação contínua, uma vez que, devido, em parte, aos recentes processos de municipalização do ensino, as políticas de formação nos municípios ainda estão por se delinear. Destaca-se, ainda, que, diante da crescente escassez de recursos que os municípios atravessam, o programa pode significar um reforço importante nos investimentos em formação.

No entanto, há elementos particulares de cada contexto que não podem ser ignorados e que podem interferir na maneira como cada sistema ressignifica e dá contornos próprios a programas externos. Mesmo considerando a margem de flexibilidade na implementação de programas dessa ordem nos municípios, é importante reconhecer que a natureza das apropriações, considerando a maneira como se estruturam as relações de poder, as formas de classificação e enquadramento e porque não dizer, as formas de resistência e ressignificação frente às múltiplas 
lógicas impostas desde a formulação desde os níveis macro ao micro pode estar gerando conhecimento pedagógico novo a partir também da ação dos gestores locais.

\section{A lógica do exercício do poder}

A teoria de Bernstein oferece a possibilidade de compreender como se dão as transformações de uma política de formação de professores formulada em nível macro até o momento em que se concretizam nos espaços escolares, localizando, nesse percurso, a recontextualização ocorrida em relação ao conhecimento pedagógico formulado como objeto de formação no âmbito das secretarias municipais de educação. A teoria ainda explicita como as relações de poder e controle podem interferir nas interações entre os sujeitos de um mesmo nível hierárquico ou entre sujeitos de diferentes níveis hierárquicos gerando a produção de uma determinada voz em seus contextos específicos. Conforme sinalizam Morais e Neves (2007)

\footnotetext{
A aplicação do modelo à análise das relações sociais que caracterizam um qualquer contexto pedagógico, mostra que, tal como ao macro-nível da estrutura da sociedade, também ao micro-nível das estruturas educacionais, é a natureza dessas relações que irá determinar, em grande parte, o papel reprodutor ou transformador da estrutura social. Daí o interesse atribuído, no contexto educacional, ao tipo de relações que se estabelecem. (MORAES E NEVES, 2007 p.121)
}

Ainda que consideremos a importância de análise das estruturas e contextos institucionais existentes nos diversos âmbitos, desde a formulação das políticas até sua realização nas escolas pelos professores, é imprescindível que, antes de tudo, reconheçamos o que nos aponta Foucault sobre a análise do poder a partir da constituição do sujeito.

Para ele é a produção do sujeito, sua constituição a partir de práticas históricas e sua relação com os outros e com as instituições o foco da análise das formas de poder que não pode ser estudado fora de sua relação com os mecanismos de dominação e exploração. Desse modo, o poder não está localizado em uma instituição específica e não só reprime, mas produz efeitos de saber e de verdade.

Foucault situa o conceito de poder observado na estrutura do Estado moderno ocidental a partir da tecnologia do poder pastoral, originada das instituições cristãs e que combina de forma astuciosa uma mistura de técnicas de individualização e dos procedimentos de totalização. Para ele esse Estado moderno representa "uma estrutura muito sofisticada, na qual os indivíduos podem ser integrados sob uma condição: que a esta individualidade se atribuísse uma nova forma, 
submetendo-a a um conjunto de modelos muito específicos." (FOUCAULT, 1995 p. 237). Esse poder individualizante e totalizador que

Foi associado a uma instituição religiosa definida, ampliou-se subitamente por todo o corpo social; encontrou apoio numa multiplicidade de instituições. E, em vez de um poder pastoral e de um poder político, mais ou menos ligados um ao outro, mais ou menos rivais, havia uma "tática" individualizante que caracterizava uma série de poderes: da família, da medicina, da psiquiatria, da educação e dos empregadores. (FOUCAULT, 1995 p.238)

Por isso, Foucault afirma que esse sujeito constituído através de práticas de sujeição historicamente construídas coloca ao homem a tarefa para além de reconhecer-se, mas de negar o que é, livrando-se dos mecanismos de individualização e totalização impostos pelas estruturas do poder moderno.

Importante na definição de poder é sua relação com a verdade ou com o que apresenta como produção da verdade. As ideias de conhecimento e verdade são produzidas a partir dos interesses e das disputas entre indivíduos e grupos e esta verdade não existe sem o poder.

\footnotetext{
Cada sociedade tem seu regime de verdade, sua "política geral" de verdade: isto é, os tipos de discurso que ela acolhe e faz funcionar como verdadeiros; os mecanismos e as instâncias que permitem distinguir os enunciados verdadeiros dos falsos, a maneira como se sanciona uns e outros; as técnicas e os procedimentos que são valorizados para a obtenção da verdade; o estatuto daqueles que tem o encargo de dizer o que funciona como verdadeiro (FOUCAULT, 1979 p. 12).
}

As características dessa verdade produzida nas sociedades são caracterizadas por Foucault a partir de cinco traços historicamente importantes: 1) centra-se na forma do discurso científico; 2) está submetida ao político e ao econômico 3) é amplamente difundida e consumida pelos diversos aparelhos de informação; 4) é produzida e difundida pelos grandes aparelhos políticos e econômicos; 5) é objeto de confrontos através das lutas ideológicas. Para ele, a verdade é constituída "pelo conjunto das regras segundo as quais se distingue o verdadeiro do falso e se atribui ao verdadeiro, efeitos específicos de poder" (FOUCAULT, 1979 p. 13). É nessa produção do sujeito determinado pelas práticas de produção de verdade e de poder que se encontra a racionalidade do "como" esse poder é exercido. São as estratégias que, na modernidade, estão para além da repressão, uma vez que não é na negação, na proibição que está a sua força, pois a manutenção do poder está justamente por permear o todo, produzir coisas, induzir ao prazer, formar saber, produzir discurso.

O poder que interessa na análise de Foucault está ligado diretamente com o poder que se exerce uns sobre os outros, nas relações e que não é necessariamente, fruto de consenso, de consentimento. Para ele o poder só pode ser reconhecido no ato de seu exercício e se difere das capacidades objetivas do sujeito e das relações de comunicação, mesmo apontando essas duas 
formas como complementares no bloco capacidade-comunicação-poder, onde a aplicação das capacidades técnicas e o jogo das comunicações estão, junto às relações de poder, definidos como disciplina.

Ainda que não seja necessariamente fruto de consentimento, também não é necessariamente, produto de violência, embora possa incluir um e outro.

\begin{abstract}
Ele não é em si mesmo uma violência, que às vezes se esconderia, ou um consentimento, que implicitamente, se reconduziria. Ele é um conjunto de ações sobre ações possíveis; ele opera sobre o campo das possibilidades onde se inscreve o comportamento dos sujeitos ativos; ele incita, induz, desvia, facilita ou torna mais difícil, amplia ou limita, torna mais ou menos provável; no limite, ele coage ou impede absolutamente, mas é sempre uma maneira de agir sobre um ou vários sujeitos ativos, e o quanto eles agem ou são suscetíveis ao agir. Uma ação sobre ações. (FOUCAULT, 1995 p. 243)
\end{abstract}

Nesse sentido o poder se exercerá muito mais conduzindo condutas, estabelecendo a forma pela qual as ações sobre as ações se constituirão no governo, estruturado pelo eventual campo de atuação dos outros. A esse governo dos indivíduos ou de grupos, uns pelos outros, inclui-se um fator preponderante que é a liberdade, uma vez que só há poder se houver sujeitos ou grupos livres. Foucault explica que nas interações onde as relações de poder estão saturadas, como na escravidão, a relação de poder inexiste, de modo que a insubmissão da liberdade e o poder não podem ser separados.

Para que se compreenda o poder nas instituições Foucault sugere que seja analisado, antes de qualquer coisa, como o poder se constitui na sociedade, a partir: 1) do estabelecimento sobre como as diferenças que se originam do privilégio e que para o autor representam, ao mesmo tempo, causa e efeito; 2) dos objetivos perseguidos por aqueles que agem sobre a ação dos outros e que necessitam manter privilégios, por exemplo; 3) das modalidades instrumentais, ou seja, a partir de todo tipo de mecanismo utilizado como forma de obter e consolidar o poder; 4) das formas de institucionalização, ou seja, estruturas jurídicas, fenômenos de hábito e de moda; 5) dos graus de racionalização, representados pelo funcionamento das relações de poder a partir da eficácia dos instrumentos e do grau de adequação necessários. Justamente pelo fato de que a análise do poder exigir que se considere seu enraizamento no conjunto da rede social, o autor ressalta que a análise da ação sobre a ação dos outros deve privilegiar "as múltiplas formas de disparidade individual, de objetivos, de determinada aplicação do poder sobre nós mesmos e sobre os outros, de institucionalização mais ou menos setorial ou global, organização mais ou menos refletida, que definem formas diferentes de poder" (FOUCAULT, 1995 p. 247).

Foucault afirma que nesse desenvolvimento da ação sobre a ação dos outros são utilizadas as chamadas "estratégias de poder", utilizadas para fazer funcionar e manter as formas de poder e 
são constituídas de uma série de mecanismos com a finalidade de obter vitória nas mais diversas relações de poder existentes. No entanto,

[..] o ponto mais importante é evidentemente a relação entre relações de poder e estratégias de confronto. Pois, se é verdade que no centro das relações de poder e como condição permanente de sua existência, há uma "insubmissão" e liberdades essencialmente renitentes, não há relação de poder sem resistência, sem escapatória ou fuga, sem inversão eventual (FOUCAULT, 1995 p. 248).

A existência da liberdade representa uma condição para que também se estabeleçam relações de poder que podem regular as formas de resistência ao instituído. Bernstein aprofunda ainda mais as explicações sobre as relações de poder através do conceito de "código", que se configura a partir das formas de classificação e de enquadramento geradas pelas relações de poder e controle de cada contexto. Conforme sinaliza, classificação e enquadramento poderão se apresentar nas mais variadas gradações, o que não quer dizer que haja mais ou menos poder conforme a intensidade de classificação e enquadramento verificado nos contextos. Significará apenas um poder implícito. Para Bernstein,

Os princípios dominantes da formação social selecionam/limitam as práticas organizacionais, discursivas, relacionais e as práticas de transmissão, isto é, os valores de classificação e enquadramento e, portanto, os códigos dominantes. O grau de eficácia dessa seleção/limitação depende do espaço concedido às autonomias relativas e do equilíbrio do poder. (BERNSTEIN, 1990 p. 64)

São essas variadas formas de configuração do código que poderão gerar diferentes vozes, determinando o tipo de mensagem reproduzida/produzida ${ }^{2}$ por cada indivíduo ou grupo.

\section{Autonomia: um caminho para a resistência?}

Ao partir do que seria a Aufklärung, o esclarecimento proposto por Kant, Foucault assume uma universalidade de valores e normas diferentes daquelas propostas por Kant, colocando à prova a ideia de maioridade defendida pela perspectiva kantiana que estabelece sua existência a partir da “modificação da relação preexistente entre a vontade, a autoridade e o uso da razão" (FOUCAULT, 2008 p. 337). As críticas ao modelo de esclarecimento e uso da razão propostos por Kant se dão justamente pelo fato de que esse uso está restrito aos limites e às regras rígidos, sobretudo quando esclarece o que seria o uso público e o uso privado da razão, levando-nos a reconhecer que esse uso da razão descrito por Kant deixaria pouco espaço para a crítica e para o uso livre da razão.

No entanto, para além de uma posição a favor ou contra a Aufklärung, Foucault aponta que

É preciso tentar fazer a análise de nós mesmos como seres historicamente determinados, até certo ponto, pela Aufklärung. O que implica uma série de pesquisas históricas tão precisas quanto possível; e essas pesquisas não serão orientadas retrospectivamente na direção do "núcleo essencial da racionalidade" que se pode encontrar na Aufklärung e 
que se poderia salvar inteiramente no estado da causa; elas seriam orientadas na direção dos limites atuais do necessário": ou seja, na direção do que não é, ou não é mais, indispensável para a constituição de nós mesmos como sujeitos autônomos. (FOUCAULT, 2008 p.345)

Para constituir-nos como sujeitos autônomos Foucault apresenta a necessidade de nos posicionarmos criticamente ao que nos é apresentado como "universal, necessário, obrigatório, qual é a parte do que é singular, contingente e fruto de imposições arbitrárias" transpondo barreiras rígidas e exercendo uma crítica "sob a forma de ultrapassagem do possível" (FOUCAULT, 2008 p. 347).

A questão que o próprio Foucault apresenta é “[...] não há risco de nos deixarmos determinar por estruturas mais gerais, sobre as quais tendemos a não ter nem consciência nem domínio?" (FOUCAULT, 2008, p. 349). Colocado de outro modo, é possível de fato sentir, pensar e agir de forma autônoma diante de estruturas já estabelecidas, e no caso da discussão sobre políticas de formação estabelecidas, agir sobre elas de modo que se tornem significativas e coerentes com os contextos para o quais elas foram pensadas? Estariam os sujeitos, nesse caso, exercendo de fato autonomia?

Parte da resposta dada por Foucault à questão das estruturas já estabelecidas diz respeito à maneira pela qual os homens assumem o que lhes é dado, ou seja, "as formas de racionalidade que organizam as maneiras de fazer (o que poderíamos chamar de seu aspecto tecnológico), e a liberdade com a qual eles agem nesses sistemas práticos, reagindo ao que os outros fazem, modificando até certo ponto as regras do jogo" (FOUCAULT, 2008 p. 350). Olhando desse modo, estaríamos diante de uma possibilidade de subversão das regras, de uma apropriação crítica daquilo que nos é dado e apresentado através de estruturas rígidas. Mas esse exercício de autonomia estaria condicionado e seria decorrente, segundo Foucault, dos domínios relacionados a três eixos: 1) o eixo do saber, que estaria relacionado ao domínio sobre as coisas e à nossa constituição como sujeitos do saber; 2) o eixo do poder, que diz respeito às nossas relações com os outros, como nos constituímos como seres que sofrem ou exercem relações de poder; 3) o eixo da ética, que se refere a como nos constituímos como sujeitos morais em nossas ações, estabelecendo relações conosco mesmos. Entendemos desse modo, que a resposta seria afirmativa se as problematizações forem realizadas a partir de uma coerência metodológica, teórica e prática: metodológica quando olhamos para a racionalidade presente nas estratégias do fazer, teórica, quando os eixos do saber, do poder e da ética estiverem sendo historicamente problematizados, e prática quando a reflexão históricocrítica estiver sendo colocada à prova da prática concreta. 


\section{Considerações finais}

Para discutir a questão do uso consciente da razão e da autonomia como uma forma de construir sentidos nos contextos de estruturas mais rígidas, previamente determinadas, situamos o contexto educacional no conjunto mais amplo da sociedade do desempenho, guiada pelos valores da economia neoliberal. Percorremos as formas pelas quais as relações de poder se configuram e definem o modelo de discurso pedagógico, gerando uma determinada voz na apropriação das políticas educacionais formuladas nos macro níveis das estruturas de governo e trouxemos as contribuições de Foucault quando se refere ao que ousamos denominar mecanismos de resistência, construídos a partir de decisões sobre como os homens se posicionam racionalmente, teoricamente e eticamente frente às grandes problemáticas de nosso tempo.

As atuais configurações da sociedade do desempenho e, mais especificamente, suas consequências devastadoras na formulação das políticas educacionais e em especial as políticas de formação continuada no país parecem nos levar a uma perda total das esperanças de construir uma educação que de fato proporcione aos indivíduos o empoderamento necessário às formas de resistência para esse tempo. Tal desesperança penetra-nos a alma e nos impulsiona a aderir à racionalidade do "deixar morrer", da desconsideração completa do outro, de uma lógica de competição, que, no caso da escola, se apresenta como perdedora. Ainda assim, parece haver evidências de que posicionamentos racionais, teóricos e éticos tem impulsionado formas de resistência diversas e gerado novas construções de sentido e é o que a nossa pesquisa em desenvolvimento investiga.

Foucault propõe possibilidades do uso consciente da razão, da opção ética e de "coragem da verdade" e acreditamos que é preciso jogar luz nas tentativas que, ainda isoladas, se desenvolvem e promovem a vida através da escola, essa instituição fundamental que para muitos pode representar a última possibilidade de constituir-se como sujeito consciente e por que não dizer, mais humano. É preciso desvendar esse homem das fronteiras, aquele que, como sugere Lefebvre, mesmo frente a todas as estruturas impostas

\footnotetext{
Suporta uma tensão que iria matar os outros: está simultaneamente dentro e fora, incluído e excluído [...]. Vive esta contradição. [...] O homem das fronteiras segue caminhos que primeiro surpreendem, então eles se tornam rotas e passam então por evidências. Caminha ao longo das linhas divisórias das águas e escolhe o caminho que vai em direção ao horizonte. Às vezes passa pelas terras prometidas; não entra nelas. Esse é o seu teste. Ele sempre vai para outras terras, para o horizonte dos horizontes, de momento a momento, até ver as linhas distantes de um continente inexplorado. (LEFEBRE, 1983, p. 227)
}

Frente aos desafios impostos à escola de hoje pelos valores de uma sociedade de mercado e pelas mais diversas estratégias de poder existentes nas macro e micro instituições são aqueles 
capazes de ousar no exercício da autonomia a partir da perspectiva apresentada os que estarão realizando a verdadeira obra na construção de uma educação verdadeiramente de qualidade. "Vivemos numa loja mercantil transparente, somos supervisionados e governados. Já é tempo de rompermos com essa casa mercantil. Já é hora de transformar essa casa mercantil novamente numa moradia, numa casa de festas, onde valha mesmo a pena viver" (HAN, 2017 p. 128).

\section{Referências}

BERNSTEIN, Basil. A estruturação do discurso pedagógico. Classes, códigos e controle. Petrópolis: Vozes, 1990.

BERNSTEIN, Basil. Poder, Educacion y Conciencia: Sociología de la Transmisión Cultural. Santiago: Cide Ediciones, 1988.

BRANCO, Castelo Guilherme; Veiga-Neto, Alfredo (org.). Foucault: Filosofia e Política. Belo Horizonte : Autêntica Editora, 2011.

MAINARDES, Jefferson. Abordagem do ciclo de políticas: Uma contribuição para a análise de políticas educacionais. Campinas: Educação e Sociedade, vol. 27, n. 94 p. 47- 69, jan/abr. 2006.

MORAIS, Ana Maria; NEVES, Isabel. A teoria de Basil Bernstein: alguns aspectos fundamentais. Ponta Grossa: Práxis Educativa, v2, n. 2, p. 115-130, jul-dez. 2007.

DUARTE, André. Foucault e a governamentalidade: genealogia do liberalismo e do Estado moderno. In: CASTELO BRANCO, Guilherme; VEIGA-NETO, Alfredo (Orgs.). Foucault, filosofia e política. Belo Horizonte: Autêntica, 2011.

FOUCAULT, Michel. O que são as luzes? In: FOUCAULT, Michel.. Ditos e escritos II. Arqueologia das ciência e história dos Sistemas do Pensamento. Rio de Janeiro: Forense Universitária, 2008, p. 235 - 351.

FOUCAULT, Michel. O sujeito e o poder. In: RABINOW, Paul; DREYFUS, Hubert. Uma trajetória filosófica. Para além do estruturalismo e da hermenêutica. Rio de Janeiro: Forense Universitária, 1995.

FOUCAULT, Michel. O olho do poder. In: FOUCAULT, Michel. Microfísica do poder. Rio de Janeiro: Edições Graal, 1979.

FOUCAULT, Michel. A governamentalidade. In: FOUCAULT, Michel. Microfísica do poder. Rio de Janeiro: Edições Graal, 1979.

FOUCAULT, Michel. Aula de 17 de março de 1976. In: FOUCAULT, Michel. Em defesa da sociedade. São Paulo: Martins Fontes, 2005.

FOUCAULT, Michel. Direito de morte e poder sobre a vida. In: FOUCAULT, Michel. História da sexualidade I. A vontade de saber. Edições Graal: Rio de Janeiro, 1988.

HAN, Buyng-Chul. Sociedade do cansaço. Petrópolis, RJ: Vozes, 2015. 
LEFEBVRE, H. La presencia y la ausencia - contribuición a la teoria de las representaciones. México: Fondo de Cultura Económica, 1983. edição original: 1980.

\section{Notas}

1. Pesquisa de doutorado em desenvolvimento intitulada "As formas de Apropriação pelos sistemas municipais de Educação da formação oferecida pelo Pacto Nacional pela Alfabetização na Idade Certa" (Título provisório).

2. Para Bernstein, "produção e reprodução tem sua base material em categorias e práticas; que as categorias são constituídas pela divisão social do trabalho e que as práticas são constituídas pelas relações sociais no interior da produção/reprodução; que as categorias constituem "vozes" e que as práticas constituem "mensagem"; que a mensagem depende da "vOz" e que o sujeito é uma relação dialética entre "voz" e "mensagem". (BERNSTEIN, 1990, p. 48). 